\title{
Lung cancer and occupation: results of a multicentre case-control study
}

\author{
A Morabia, S Markowitz, K Garibaldi, E L Wynder
}

\begin{abstract}
The objective of the current study was to estimate the risk of lung cancer attributable to occupational factors and not due to tobacco. At 24 hospitals in nine metropolitan areas in the United States, 1793 male lung cancer cases were matched for race, age, hospital, year of interview, and cigarette smoking (never smoker, ex-smoker, smoker (1-19 and $\geqslant 20$ cigarettes per day)) to two types of controls (cancer and non-cancer hospital patients). Information on usual occupation, exposure to specific potential carcinogens, and cigarette smoking was obtained by interview. Risk of lung cancer was increased significantly for electricians; sheetmetal workers and tinsmiths; bookbinders and related printing trade workers; cranemen, derrickmen, and hoistmen; moulders, heat treaters, annealers and other heated metal workers; and construction labourers. All of these occupations are potentially exposed to known carcinogens. Odds ratios (ORs) were increased for exposure to coal dust (adjusted OR $=1 \cdot 5 ; 95 \%$ confidence

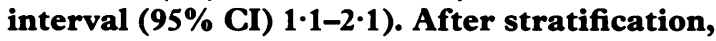
this association was statistically significant only after 10 or more years of exposure. Lung cancer was also related to exposure to asbestos (adjusted OR $=1.8 ; 95 \%$ CI 1.5-2.2). The ORs increased with increasing duration of exposure to asbestos for all smoking categories except for current smokers of 1-19 cigarettes per day. The statistical power to detect ORs among occupations that were previously reported to be at increased risk of lung cancer but that failed to show an OR of at least 1.5 in the current study was small. The cumulative
\end{abstract}

American Health Foundation, 320 E 43 Street, New York, New York 10017, USA

A Morabia, E L Wynder

Clinical Epidemiology Unit, University Canton

Hospital, 1211 Geneva 4, Switzerland

A Morabia

Division of Environmental and Occupational

Medicine, Department of Community Medicine, Mt

Sinai School of Medicine

S Markowitz, K Garibaldi population attributable risk (PAR) of lung cancer due to occupation was $\mathbf{9 \cdot 2} \%$. It is concluded that occupational factors play an important part in the development of lung cancer independently of cigarette smoking. Because occupations at high risk of lung cancer were under-represented, the cumulative PAR of the present study is likely to be an underestimate of the true contribution of occupation to risk of lung cancer.

That specific chemical and physical agents including asbestos, arsenic, radon daughters, nickel, coke oven emissions, and chromates, and the occupations that involve exposure to these agents increase the risk of lung cancer is well documented..$^{1-3}$ Risk of lung cancer is also increased in other occupational groups such as butchers that do not involve exposure to known lung carcinogens. ${ }^{4-6}$ Nevertheless, despite an abundance of publications, the nature and magnitude of the relation between lung cancer and occupation have not been fully delineated.

In 1982, Dubrow and Wegman published a comprehensive review and discussion of existing epidemiological studies relating occupation to various cancers. ${ }^{7}$ They identified 34 occupations with consistent evidence of an excess risk of lung cancer, mostly in the manufacturing sector and construction trades, and, to a lesser extent, in the transportation and service sectors. The publications encompassed by their review, however, often contained inadequate information on cigarette smoking and, hence, could not account for cigarette smoking as a confounding factor.

In the past 10 years, at least 13 case-control studies have examined possible occupational risk factors for lung cancer ${ }^{8-20}$ and have confirmed, to varying degrees, many of the associations highlighted by Dubrow and Wegmen. ${ }^{7}$ Unlike previous studies, the effects of occupational exposures were adjusted for cigarette smoking, but the power to detect associations between occupations and lung cancer was principally limited by sample size and by the distribution of occupations in the geographical area under study. These two related factors serve to explain, in part, discrepancies among studies. 
In the present study we examine the occupational contribution to lung cancer in a longstanding, multicentre case-control study. Advantages of the current study include a large sample of cases and controls, inclusion of multiple geographical locations, personal interview of cases and controls, histological confirmation of all cases, and detailed smoking histories.

\section{Materials and methods}

THE AMERICAN HEALTH FOUNDATION DATABASE

Since 1969, the American Health Foundation has conducted a longstanding hospital based casecontrol study. ${ }^{21}$ Between 1980 and 1989, 1793 male patients with the diagnosis of lung cancer (International Classification of Diseases, 9th edition, rubric $162 \cdot 0-162 \cdot 9$ ) were identified in 24 hospitals in the following cities or areas: Detroit, Chicago, Philadelphia, Pittsburgh, New York, Long Island, San Francisco, Birmingham, and Atlanta. The objective was to interview all cases with tobacco related conditions (cancers of the lung, upper respiratory, and digestive tracts, pancreas, kidney and bladder, and myocardial infarctions) that are admitted to participating hospitals. All cases were confirmed histologically by review of the pathology report. For each case, one or two patients of the same age, race, hospital, and date of admission, but admitted for a condition not related to tobacco consumption, were interviewed as controls.

\section{PRESENT STUDY DESIGN}

To study the relation between occupational exposures and cancer we used the American Health Foundation database to design a specific case-control study. All 1793 patients with lung cancer were included as cases. For each case, we selected at least one and usually two controls from the pool of all patients without lung cancer, including tobacco related diagnoses, who were interviewed between 1980 and 1989. Each control was matched to the case on the following variables: race (black, white), age (within five years), hospital, and cigarette smoking history (never smoker, ex-smoker, current smoker of 1-19 cigarettes per day, and current smoker of 20 or more cigarettes per day). All controls were interviewed within two years of the case interview.

Diagnoses among the 3228 controls included cancers $(2230,(69.0 \%))$ of the following primary sites: bladder $(11 \cdot 2 \%)$, gastrointestinal $(10 \cdot 2 \%)$, oral cavity and pharynx $(9.0 \%)$, prostate $(4.5 \%)$, larynx $(4 \cdot 1 \%)$, lymphoma $(3 \cdot 1 \%)$, sarcoma $(2 \cdot 4 \%)$, leukaemia and myeloma $(2 \cdot 2 \%)$, and other $(22 \cdot 3 \%)$. Non-cancer controls (998 (31.0\%)) had musculoskeletal $(6.8 \%)$, thromboembolic $(4.5 \%)$, cardiovascular $(3 \cdot 4 \%)$, benign neoplastic $(2 \cdot 2 \%)$, and other diseases $(14 \cdot 1 \%)$.
Information on sociodemographic and anthropometric characteristics, and cigarette smoking was collected from the study participants through a structured, standardised questionnaire administered by trained interviewers. The occupational history included job title ("What has been your usual occupation?") and specific exposure to a list of 44 different agents ("Have you been exposed to any of the following substances, either on the job or while working on a hobby, during eight hours a week or more for at least one year?"). Subjects interviewed between 1980 and $1984(n=2686)$ could report the duration of occupational exposure for up to two different agents only. The interviewer recorded the two agents that the subject perceived to be the most important. In 1985 the occupational history was expanded so that participants $(n=2335)$ could report the duration of exposure to a maximum of six different agents. Since 1985 the questionnaire also recorded whether the exposure to the agent had occurred at a job or while engaging in a hobby. Job titles were coded according to an abbreviated list of the United States Bureau of Census codes. ${ }^{22}$

\section{STATISTICAL ANALYSIS}

Self reported occupational exposures were coded as ever or never exposed. When an exposure was reported as related to a hobby, its duration was divided by two to give it one half the weight of a job exposure, assuming that a job exposure may be at least twice the frequency or intensity of a hobby exposure. The analysis by duration of exposure $(<10$ years, $\geqslant 10$ years) was limited to occupational exposures that were found related to lung cancer in the ever $v$ never exposed analysis.

Unconditional logistic regression ${ }^{23}$ was used to compute odds ratios (ORs) adjusted for all matching factors-that is, age, cigarette smoking (never, exsmoking, current one to 19 cigarettes per day, current 20 or more cigarettes per day), geographical area (New York; Atlanta and Birmingham combined; Detroit; Chicago; San Francisco; Philadelphia and Pittsburgh combined), race, and questionnaire version (two categories corresponding to the years of interview 1980-4 and 1985-9). As shown by Breslow et $a l,{ }^{24}$ an unmatched analysis of a matched casecontrol study is more efficient than the matched analysis and produces similar ORs, given that the ORs are adjusted for the matching factors.

Trends in the ORs and potential interactions between job exposure and smoking were assessed using logistic regression. When assessing the ORs of lung cancer related to exposure to asbestos, subjects having gastrointestinal, oropharyngeal, and laryngeal cancers were removed from the cancer controls, as there is evidence that these cancers are causally related to asbestos. ${ }^{25-27}$ Departure from the assumption of the logistic regression model was checked by 
Table 1 Distribution of occupations among controls $v$ United States general population

\begin{tabular}{|c|c|c|c|c|c|}
\hline & & \multicolumn{2}{|c|}{ Study controls } & \multicolumn{2}{|c|}{1980 US population } \\
\hline \multicolumn{2}{|c|}{ Occupation (Census code) } & No & $(\%)$ & No & $(\%)$ \\
\hline $\begin{array}{l}\text { II } \\
\text { III } \\
\text { IV } \\
\text { V } \\
\text { VI } \\
\text { VII } \\
\text { VIII } \\
\text { IX } \\
\text { X } \\
\text { No code }\end{array}$ & $\begin{array}{l}\text { Managers }(201-245) \\
\text { Professionals and technicians (001-195) } \\
\text { Sales workers }(260-280) \\
\text { Administrative support and clerical workers (301-395) } \\
\text { Service workers }(901-984) \\
\text { Farming, forestry, and fishing workers }(801-824) \\
\text { Skilled crafts and repair workers }(401-580) \\
\text { Operatives, assemblers, inspectors }(601-695) \\
\text { Transportation workers (701-715) } \\
\text { Labourers (740-785) }\end{array}$ & $\begin{array}{r}499 \\
647 \\
293 \\
167 \\
119 \\
19 \\
897 \\
264 \\
194 \\
125 \\
4\end{array}$ & $\begin{array}{r}(15 \cdot 5) \\
(20 \cdot 0) \\
(9 \cdot 1) \\
(5 \cdot 2) \\
(3 \cdot 7) \\
(0 \cdot 6) \\
(27 \cdot 8) \\
(8 \cdot 2) \\
(6 \cdot 0) \\
(3 \cdot 9) \\
(0 \cdot 1)\end{array}$ & $\begin{array}{r}7063304 \\
7812583 \\
5088664 \\
3854322 \\
5177580 \\
2406989 \\
11616225 \\
5438751 \\
4041532 \\
3504760 \\
-\end{array}$ & $\begin{array}{r}(12 \cdot 6) \\
(13 \cdot 9) \\
(9 \cdot 1) \\
(6 \cdot 9) \\
(9 \cdot 3) \\
(4 \cdot 3) \\
(20 \cdot 7) \\
(9 \cdot 7) \\
(7 \cdot 2) \\
(6 \cdot 3) \\
-\end{array}$ \\
\hline Total & & 3228 & $(100)$ & 56004710 & $(100)$ \\
\hline
\end{tabular}

examination of the stratum specific differences between observed and expected numbers of cases. ${ }^{23}$

In the results section we report adjusted ORs for job titles only if (1) the OR is greater than or equal to 1.5 , and (2) if at least five subjects (cases and controls) have the job title.

Adjusted population attributable risk per cent (PAR) was computed for specific occupations using Levin's formula and the adjusted ORs. ${ }^{23}$ The prevalence of exposure in the population was obtained from census information on distribution of job categories in the United States in $1980 .{ }^{22}$ Power calculations were done using the formula for an unmatched case-control study with unequal number of cases and controls given by Schlesselman. ${ }^{28}$

\section{Results}

Because one of the objectives of the study was to estimate the PAR of lung cancer due to occupation, we compared the distribution of occupations in the study population with that of the United States

Table 2 Odds ratios and population attributable risks of lung cancer by occupation among male United States hospital patients, 1980-9

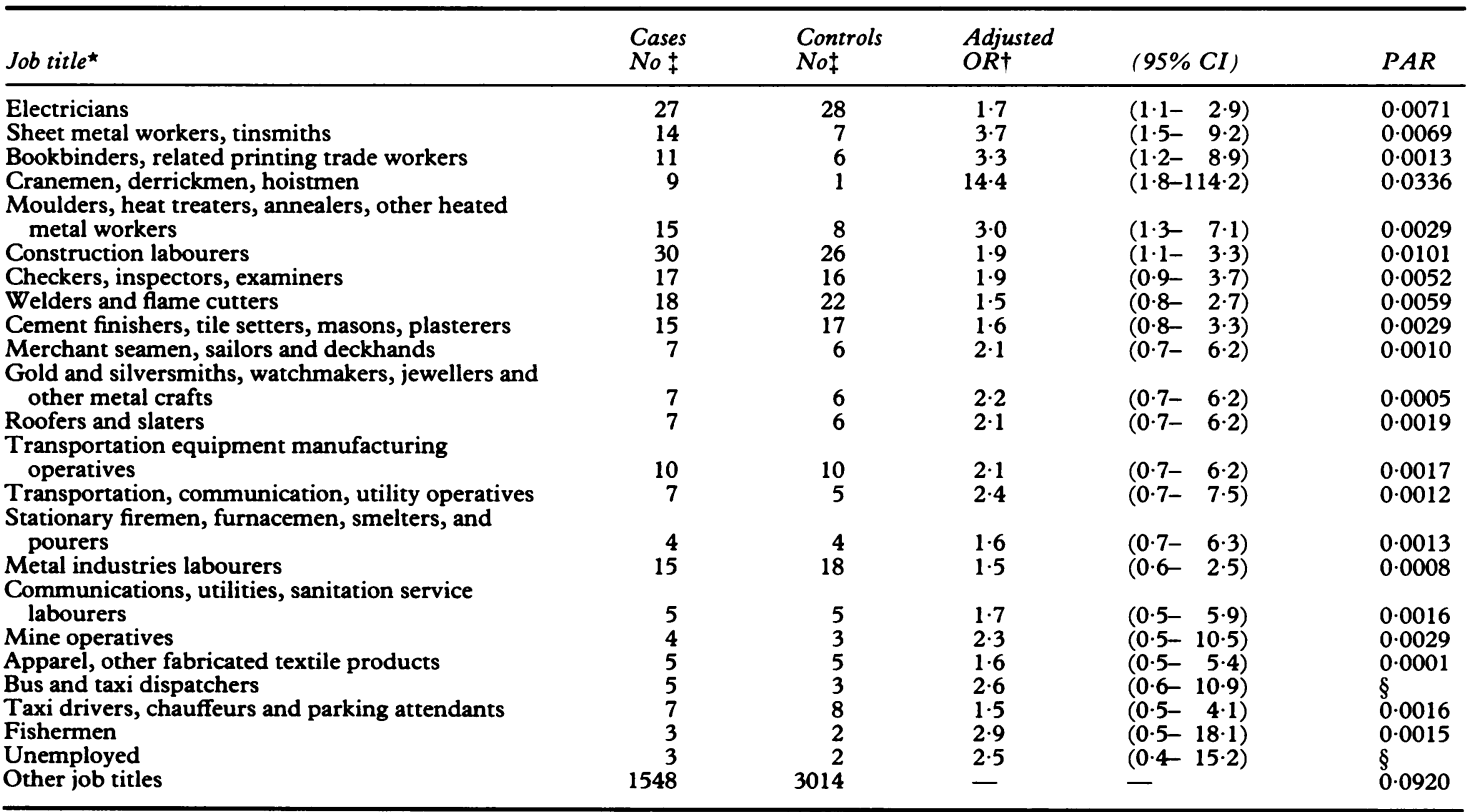

PAR = Population attributable risk.

$\star$ Job titles having at least five subjects and a crude $O R \geqslant 1 \cdot 5$.

+OR adjusted simultaneously for age, race, geographical area, questionnaire version, and smoking (never, current 1-19 cigarettes per day, current $\geqslant 20$ cigarettes per day, ex-smokers).

$\ddagger$ Total cases $=1793$. Total controls $=3228$.

$\S$ Not classified as such by the US Bureau of Census. 
Table 3 Odds ratio of lung cancer according to duration of exposure to coal dust by types of controls among male United States hospital patients, 1980-9

\begin{tabular}{|c|c|c|c|c|c|c|c|}
\hline \multirow{3}{*}{$\begin{array}{l}\text { Coal dust } \\
\text { exposure (y) }\end{array}$} & \multirow{3}{*}{$\begin{array}{l}\text { Cases } \\
(n=1793)\end{array}$} & \multicolumn{2}{|l|}{ Controls } & \multirow{2}{*}{\multicolumn{4}{|c|}{ Adjusted $O R^{\star}$}} \\
\hline & & & Non-cancer & & & & \\
\hline & & $(n=2230)$ & $(n=998)$ & $C C^{\dagger}$ & $N C \dagger$ & All & $(95 \% C I)$ \\
\hline $\begin{array}{l}\text { Never } \\
<10_{+}^{+} \\
\geqslant 10^{+}\end{array}$ & $\begin{array}{r}1721 \\
37 \\
35\end{array}$ & $\begin{array}{r}2174 \\
35 \\
21\end{array}$ & $\begin{array}{r}972 \\
14 \\
12\end{array}$ & $\begin{array}{l}1 \cdot 0 \S \\
1 \cdot 2 \\
1 \cdot 5\end{array}$ & $\begin{array}{l}1 \cdot 0 \$ \\
1 \cdot 6 \\
2 \cdot 0\end{array}$ & $\begin{array}{l}1 \cdot 08 \\
1 \cdot 3 \\
1 \cdot 7\end{array}$ & $\begin{array}{l}\text { (reference) } \\
(0 \cdot 8-2 \cdot 0) \\
(1 \cdot 1-2 \cdot 7)\end{array}$ \\
\hline
\end{tabular}

* Simultaneously adjusted for smoking, age, exposure to asbestos (ever/never), geographical area, and version of questionnaire.

$+\mathrm{CC}=$ cancer controls, $\mathrm{NC}=$ non-cancer controls.

+Median duration of exposure to coal dust among ever exposed.

$\S$ Reference group.

census in 1980. Table 1 shows that the control group of the present study contained more managers, professionals and technicians, and skilled crafts and repair workers, and fewer service workers, labourers, and farming, forestry, and fishing workers compared with the general population of the United States in 1980. Whereas the overall proportions of white collar (groups I to V) and blue collar (groups VI to X) workers are nearly identical in the study control group and the general United States population, study participants tended to be concentrated in the more highly paid occupations (managers, professionals and technicians, skilled crafts and repair workers) within both the white and blue collar categories. Also, only $7 \%$ of the study control group had job titles in the construction trades (selected titles from the categories of skilled crafts and repair workers and labourers) compared with $14 \%$ of the United States population with the same occupations.

Table 2 presents the adjusted ORs of lung cancer for all occupations with ORs $\geqslant 1.5$ and a minimum of five or more cases and controls out of a total of 102 occupations comprising at least five or more cases and controls. Adjusted ORs with a $95 \%$ confidence interval $(95 \% \mathrm{CI})$ not including unity were found for six occupational categories: electricians; sheet metal workers and tinsmiths; bookbinders and related printing trade workers; cranemen, derrickmen, and hoistmen; moulders, heat treaters, annealers and other heated metal workers; and construction labourers. Table 2 also lists three other occupations showing associations of borderline statistical significance (lower limit of $95 \% \mathrm{CI} \geqslant 0.8$ ).

Of the 44 specific exposures to occupational agents reported in the questionnaire, a statistically significant increase in OR was found for only two: coal dust (adjusted OR $=1 \cdot 5 ; 95 \% \mathrm{CI} 1 \cdot 1-2 \cdot 1)$ and asbestos (adjusted $\mathrm{OR}=1 \cdot 8 ; 95 \%$ CI $1 \cdot 5-2 \cdot 2$ ) (not shown in table). Self reported occupational exposure to coal was sufficiently common to evaluate by duration of exposure (table 3 ). The association between coal dust and lung cancer increased with increasing duration of exposure but was only significant among men who reported 10 or more years of exposure (adjusted OR $=1 \cdot 7 ; 95 \%$ CI $1 \cdot 1-2 \cdot 7)$. The association was present whether using cancer controls or non-cancer controls (table 3).

The relation between exposure to asbestos and lung cancer was evaluated after stratification by smoking (table 4). Subjects who smoked only pipes and cigars were excluded. Patients with oral, pharyngeal, laryngeal, and gastrointestinal cancers were excluded from the control group due to the known relation between these cancers and exposure to asbestos. The ORs increased with increasing duration of exposure to asbestos for all strata except

Table 4 Odds ratios ${ }^{\star}$ of lung cancer according to asbestos exposure and smoking state among male United States hospital patients, 1980-9

\begin{tabular}{|c|c|c|c|c|c|c|c|}
\hline \multirow[b]{2}{*}{$\begin{array}{l}\text { Asbestos } \\
\text { exposure (y) }\end{array}$} & \multirow[b]{2}{*}{$\begin{array}{l}\text { Cases } \\
(\text { No })\end{array}$} & \multicolumn{4}{|c|}{ Cigarette smoking $\dagger$} & \multicolumn{2}{|c|}{ All subjects } \\
\hline & & $\begin{array}{l}\text { Never } \\
(O R)^{\star}\end{array}$ & $\begin{array}{l}\text { Ex-smoker } \\
(O R)^{\star}\end{array}$ & $\begin{array}{l}1-19 \\
(O R)^{*}\end{array}$ & $\begin{array}{l}\geqslant 20 \\
(O R)^{\star}\end{array}$ & $(O R) \ddagger$ & $(95 \% C I)$ \\
\hline $\begin{array}{l}\text { Never } \\
<10 \\
\geqslant 10\end{array}$ & $\begin{array}{r}1573 \\
78 \\
112\end{array}$ & $\begin{array}{l}1.0 \dagger \\
3.8 \\
4.9\end{array}$ & $\begin{array}{l}1 \cdot 2 \\
2 \cdot 9 \\
2 \cdot 2\end{array}$ & $\begin{array}{l}1 \cdot 1 \\
0 \cdot 7 \\
1 \cdot 2\end{array}$ & $\begin{array}{l}1 \cdot 2 \\
2 \cdot 2 \\
2 \cdot 8\end{array}$ & $\begin{array}{l}1 \cdot 0 \S \\
2 \cdot 0 \\
2 \cdot 1\end{array}$ & $\begin{array}{l}\text { (Reference) } \\
(1 \cdot 4-2 \cdot 8) \\
(1 \cdot 6-2 \cdot 9)\end{array}$ \\
\hline
\end{tabular}

*Odds ratios are simultaneously adjusted for age, race, geographical area, and version of questionnaire. Controls $(\mathrm{n}=2226)$ do not include patients with cancer of the oropharynx, larynx, or of the gastrointestinal tract.

tSubjects smoking only pipe and/or cigar were excluded.

$\ddagger$ Also adjusted for smoking.

$\$$ Reference group. 
Table 5 Statistical power to detect ORs of 1.5 for lung cancer in current study among occupations previously reported to be at high risk of lung cancer

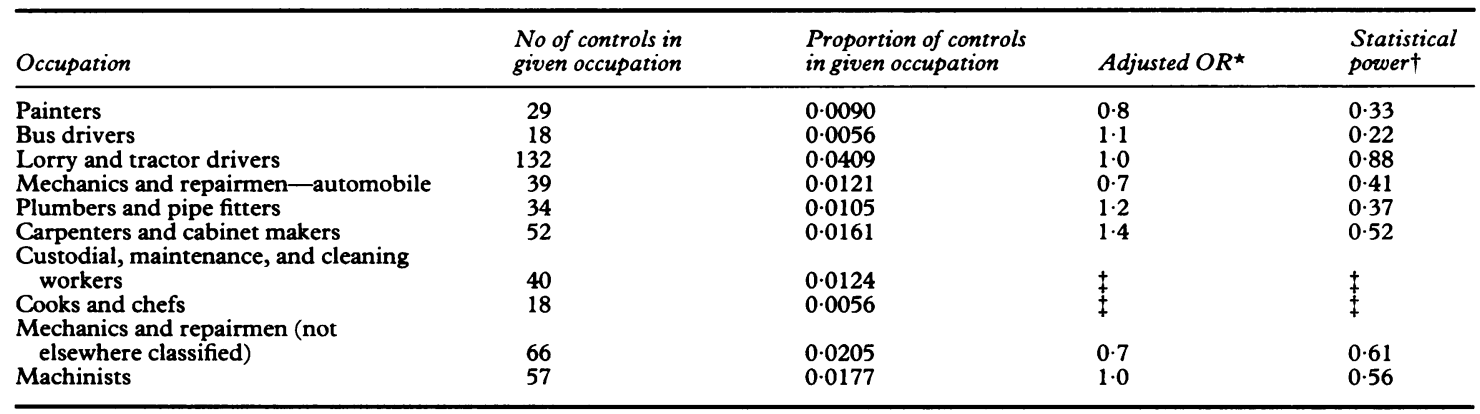

* Reference group is all other occupations; adjusted for age and smoking.

$\dagger \alpha=0.05$, two sided; ratio between controls and cases $=2$; number of controls $=3228$.

$\ddagger$ Not assessed because no cases in the study.

current smokers of 1-19 cigarettes per day. The highest ORs were found among never smokers.

For no single occupation or group of occupations, as categorised in table 1, did the increase in OR of lung cancer among non-smokers reach statistical significance. Of the 62 cases of lung cancer among non-smokers, four were lawyers and judges, three business executives, and two were in each of nine other occupations.

We examined the ability of the current study to detect risk of lung cancer from occupations in which we found an adjusted OR of lung cancer less than 1.5. Table 5 presents the statistical power of the current study to detect an OR of 1.5 setting $\alpha$ at 0.05 for occupations that have been shown repeatedly in earlier studies to be at increased risk of lung cancer. With the exception of a single occupational category, truck and tractor drivers, the (remaining nine) occupations are associated with statistical power considerably less than $0 \cdot 80$. Power was between $0 \cdot 50$ and 0.80 for carpenters and cabinet makers, mechanics and repairmen, and machinists.

The total population attributable risk (PAR) of lung cancer for all occupations with ORs greater than or equal to 1.5 based on the distribution of occupations in the general United States population is $9.2 \% .{ }^{22}$ The PARs for specific occupations are presented in the last column of table 2.

\section{Discussion}

We found six occupations with a statistically significant increase in risk of lung cancer independent of cigarette smoking. Four of them (sheet metal workers; cranemen, derrickmen, and hoistmen; heated metal workers; and construction labourers) have been shown in previous cohort studies to have an excess risk of lung cancer, but none of the previous reports controlled for cigarette smoking. ${ }^{7}$ In more recent case-control studies, Schoenberg et $a l^{16}$ and
Benhammou et al ${ }^{18}$ found an increase in ORs of lung cancer for sheet metal workers, though of less magnitude (about 1.5) and without statistical significance. Milne et al ${ }^{11}$ found a statistically significant OR of 1.9 for lung cancer among construction labourers. These and other recent case control studies had little power, however, to detect a possible association of lung cancer with employment as heated metal workers, cranemen, derrickmen, and hoistmen, due to small representation of these occupations in the study samples. All of these occupations are potentially exposed to confirmed or suspected lung carcinogens, including asbestos, nickel, chromium, polycyclic aromatic hydrocarbons, and diesel exhaust.

The statistically significant OR of lung cancer among electricians found in the present study agrees with three recent case-control studies. ${ }^{11720}$ This higher risk for lung cancer may well be explained by the exposure to asbestos experienced by electricians. ${ }^{29}$ The increase in lung cancer among bookbinders and related printing trade workers represents a new finding and may be due to exposure to solvents in adhesives and cleaning products as well as other printing chemicals.

Most of the remaining occupations showing a nonstatistically significant adjusted OR of 1.5 or greater have been previously found to carry an excess risk of lung cancer. These include cement finishers, masons, and tile setters, ${ }^{30-32}$ roofers, ${ }^{334}$ stationery firemen and furnace men, ${ }^{6163035}$ taxi drivers, ${ }^{5161834}$ fishermen, ${ }^{56}$ and workers in sheet metal and other metal industries. ${ }^{36}$ Some of these occupations are well known to be associated with recognised or suspected lung carcinogens, including asbestos, polycyclic aromatic hydrocarbons, and motor vehicle exhaust. ${ }^{137}$

The positive association between exposure to coal and lung cancer in our study is noteworthy, although difficult to interpret. The association increased with a longer duration of exposure and was found to be 
similar using cancer and non-cancer controls. Cohort studies of coal miners do not show an excess risk of lung cancer, many showing a reduced SMR for lung cancer among coal miners. ${ }^{38-40}$ On the other hand, earlier case-control studies of lung cancer show a magnitude of relative risk (RR) for lung cancer among people exposed to coal similar to that of the present study. In a study of 138 male lung cancer cases and an equal number of controls in Louisiana, Correa $e t$ al $^{12}$ reported a smoking adjusted OR of 1.5 for lung cancer and exposure to coal. In Shanghai, Levin et $a l^{19}$ found a smoking adjusted OR of 1.3 (95\% CI 1.0-1.9) for lung cancer and self-reported exposure to coal.

The finding of an association between exposure to asbestos and lung cancer was expected. ${ }^{25}$ Unlike other studies, however, ${ }^{41-43}$ we did not find the highest OR among subjects exposed to both asbestos and smoking. The strength of association between asbestos and lung cancer was highest among the nonsmokers. Data were insufficient to tell whether this finding was due to chance or whether the joint effect of asbestos and cigarette smoking was less than multiplicative. Because of the matched design of the study we could not assess whether there was additive interaction.

Evaluation of the occupational distribution among non-smoking cases of lung cancer was of limited value due to the small number of such cases (62). Even in a study of substantial size, 1793 cases of lung cancer, an assessment of factors causing lung cancer in the absence of cigarette smoking is difficult because cigarette smoking is such an important factor in the development of lung cancer, acting alone or in concert with other causes.

Our current study has numerous strengths, including the size of the sample, personal interview of cases and controls, and its broad geographical representation. Furthermore we used four categories of smoking as a matching factor (never smoker; exsmoker; current 1-19 cigarettes per day; current $\geqslant 20$ cigarettes per day). By matching controls to cases according to their current smoking state, we were able to control more efficiently the potential confounding effect of smoking. We are aware that using four categories of cigarette smoking may leave some residual confounding, but occupational lung cancer studies have uncommonly included this level of detail on cigarette smoking.

The PAR for lung cancer due to occupation has been estimated at $10 \%$ to $35 \% .{ }^{44}{ }^{45}$ The $9 \cdot 2 \%$ in this study is therefore low, well below Doll and Peto's estimate of $15 \%$ and is likely an underestimate.

In considering the extent to which our findings may be generalised, there are several reasons to expect them to fall below the true PAR. The PAR is a theoretical concept where the usual computation depends only upon $p_{c}$ (proportion of population exposed) and $R R$ through the formula PAR $=p_{e}$ $\left.(\mathrm{RR}-1) / \mathrm{p}_{\mathrm{c}}(\mathrm{RR}-1)+1\right) \cdot{ }^{47}$ Hence, it is subject to biases in both $p_{c}$ and $R R$.
If smoking is an important confounding factor, failure to adjust for it is likely to overestimate the RR, leading to over-rating the occupational contribution to total incidence of cancer. This possibility has been minimised through matching of controls to cases based on smoking history. Furthermore, the PAR concept is also one dimensional-it neglects the influence of interactions with the exposure of interest (occupation). These other exposures are frequently ignored altogether in occupational studies. ${ }^{44648} \mathrm{On}$ the other hand, there are two potentially important sources of underestimation of the true PAR: the low power due to under-representation of occupations in the geographic area under study, and the inclusion of occupations at high risk of lung cancer in the reference category of the ORs.

The distribution of occupations in our study is determined by the catchment areas of the participating hospitals. Although this was not a populationbased study, subjects were recruited in nine areas of the United States, representing a large variety of industries and services. None the less, some occupational titles were over-represented compared with the United States general population, and we thus had more power to detect statistically significant associations for these occupational groups than for others that were less numerous (table 5). This is true for most case-control studies.

Another source of underestimation of the true PAR is that the usual approach for computing ORs related to job titles is to compare subjects ever or usually employed in one occupation with subjects never or not usually employed in that occupation. In a case-control study, this approach has the advantage of treating the odds of exposure for cases and controls as random variables. On the other hand, it is likely to underestimate the true $O R$ because the reference category ("never exposed to the studied occupation") includes jobs that are at high risk of lung cancer.

It should be noted that the PARs (table 2) are point estimates, like the RRs, with their own $95 \%$ CIs, and as such should not be taken too literally. As an illustration, the $95 \% \mathrm{CI}$ of the PAR for electricians, obtained by substituting the corresponding RR in the formula for PAR is $0.001-0.019$, whereas for cranemen it is $0.002-0 \cdot 227$. Obviously, $23 \%$ of lung cancers do not arise in cranemen. Rather, the wide limits are the result of low power due to few cranemen being included in the study. What is most important is the cumulative PAR, which is the sum of the point estimates for the PARs for all the individual occupations, and for which the random errors will tend to cancel, giving a fairly stable estimate of $9 \cdot 2 \%$.

In conclusion, the cumulative PAR of the present study $(9 \cdot 2 \%)$ is likely to be a lower limit of the true contribution of occupation to lung cancer risk as it is plagued by the inherent tendency of individual epidemiological studies to underestimate the magnitude of the relation between lung cancer and occupation. Because lung cancer comprises $19 \%$ of 
total cancer incidence in men, ${ }^{49}$ this would lead to an estimate that occupation is responsible for $9.2 \% \times$ $19 \%=1.75 \%$ of all cancers in men, which is also most likely an underestimate.

We gratefully acknowledge the secretarial assistance of Katherine Gleaton and Maryline Primus and the critical comments of Dean Baker MD, MPH, Walter Stewart, PhD, and Philip Landrigan MD, MSc.

Requests for reprints to: $\mathrm{E} \mathrm{L}$ Wynder $\mathrm{MD}$, American Health Foundation, 320 E43 St, New York, New York 10017, USA.

1 International Agency for Research on Cancer. Monographs on the evaluations of the carcinogenic risk of chemicals to humans. Lyon: IARC, 1982;suppl 4:1-29.

2 Lemen RA. Occupationally induced lung cancer, epidemiology. In: Merchant J. Occupational Respiratory Diseases. Washington DC: US Dept of Health and Human Services, 1986. (DHHS Publ No 86-102;629-56.)

3 Frank AL. Occupational cancer of the respiratory tract. In: Brandt-Rauf P, ed. Occupation, cancer and carcinogenesis: Occupational medicine, state of the art reviews. Philadelphia: Hanley and Belfus, 1987:71-84.

4 Alderson M. Occupational cancer. Boston: Butterworths, 1986.

5 Buell P, Dunn JE, Breslow L. The occupational-social class risks of cancer mortality in men. Journal of Chronic Diseases $1960 ; 12: 600-21$.

6 Frazier TM, Wegman DH. Exploring the use of death certificates as a component of an occupational health surveillance system. Am J Public Health 1979;69:718-20.

7 Dubrow R, Wegman D. Setting priorities for occupational cancer research and control: Synthesis of the results of occupational disease surveillance studies. J Natl Cancer Inst 1983;71:1123-42.

8 Blot WJ, Morris LE, Stroube R, et al. Lung and laryngeal cancer in relation to shipyard employment in coastal Virginia. $J$ Natl Cancer Inst 1980;65:571-5.

9 Blot WJ, Davies JE, Brown LM, et al. Occupation and the high risk of lung cancer in Northeast Florida. Cancer 1982;50: 364-71.

10 Blot WJ, Brown LM, Pottern LM, Stone BJ, Fraumeni JF. Lung cancer among long-term steel workers. Am J Epidemiol 1983;117:706-16.

11 Milne KL, Sandler D, Everson RB, Brown SM. Lung cancer and occupation in Alameda county: a death certificate casecontrol study. Am J Ind Med 1983;4:565-75.

12 Correa P, Pickle LW, Fontham E, et al. The causes of lung cancer in Louisiana. In: Mizell M, Correa P, eds. Lung cancer: causes and prevention. Deerfield Beach: Verlag Cheine International, 1983:73-82.

13 Pastorino U, Berrino F, Gervasio A, Pesenti V, Riboli E, Crosignani P. Proportion of lung cancers due to occupational exposure. Int J Cancer 1984;33:231-7.

14 Kjuus H, Langard S, Skjeerven R. A case-referent study of lung cancer, occupational exposures and smoking. Scand $J$ Work Environ Health 1986;12:203-9.

15 Lerchen ML, Wiggins CL, Samet JM. Lung cancer and occupation in New Mexico. J Natl Cancer Inst 1987;79. 639-45.

16 Schoenberg JB, Stemhagen A, Mason TJ, Patterson J, Bill J, Altman R. Occupation and lung cancer risk among New Jersey white males. J Natl Cancer Inst 1987;79:13-21.

17 Damber LA, Larsson LG. Occupation and male lung cancer: a case control study in Northern Sweden. Br J Ind Med 1987; 44:446-53.

18 Benhamou $\dot{S}$, Benhamou E, Flamant R. Occupational risk factors of lung cancer in a French case-control study. $\mathrm{Br} J$ Ind Med 1988;45:231-3.

19 Levin LI, Zheng W, Blot WJ, Gao YT, Fraumeni JF Jr. Occupation and lung cancer in Shanghai: a case-control study. Br J Ind Med 1988;45:450-8.

20 Ronco G, Ciccone G, Mirabelli D, Troia B, Vineis P. Occupation and lung cancer in two industrialized areas of Northern Italy. Int J Cancer 1988;41:354-8.

21 Wynder EL, Stellman SD. Comparative epidemiology of tobacco-related cancers. Cancer Res 1977;37:4608-22.

22 US Department of Commerce, Bureau of Census: 1980 Census of Population. Characteristics of the Population on Chapter D, detailed population characteristics. Washington DC: US Summary PC80-1-D1-A, 1980.

23 Breslow NE, Day NE. Statistical methods in cancer research, Vol 1-The analysis of case control studies. Lyon: International Agency for Research on Cancer, 1980. (IARC Sci Publ No 32.)

24 Breslow NE, Day NE, Halverson KT, Prentice RL, Sabai C. Estimation of multiple relative risk functions in matched case control studies. Am J Epidemiol 1978;108:299-307.

25 Selikoff KJ, Lee DHK. Asbestos and disease. New York: Academic Press, 1978.

26 Doll R, Peto J. Other asbestos-related neoplasms. In: Antman K, Aisner J, eds. Asbestos-related malignancy. New York: Grune and Stratton, 1987:81-96.

27 Frumkin H, Berlin J. Asbestos exposure and gastrointestinal malignancy: review and meta-analysis. Am J Ind Med 1988;14: 79-96.

28 Schlesselman JJ. Case-control studies: design, conduct analysis. New York: Oxford University Press, 1982.

29 Hodgson $M$, Parkinson D, Sabo S, Owens GR, Feist J. Asbestosis and electricians. J Occup Med 1988;30:638-40.

30 Breslow L, Hoaglin L, Rasmussen G, Abrams HK. Occupations and cigarette smoking as factors in lung cancer. Am J Public Health 1954;44:171-81.

31 Morrison SI. Occupational mortality in Scotland. Br J Ind Med 1957;14:130-2.

32 Howe GR, Lindsay J, Miller AB. Cancer incidence and mortality in relation to occupation in 700,000 members of the Canadian labor force. Cancer Detect Prev 1980;3:487-97.

33 Hammond EC, Selikoff IJ, Lawther PL, Seidman H. Inhalation of benzopyrene and cancer in man. Ann N Y Acad Sci 1976; 271:116-24.

34 Menck HR, Henderson BE. Occupational differences in rates of lung cancer. $J$ Occup Med 1976;18:797-801.

35 Decoufle P, Lloyd JW, Salvin LG. Mortality by cause among stationary engineers and stationary firemen. J Occup Med 1977;19:679-82

36 Coggon D, Pannett B, Osmond C, Acheson ED. A survey of cancer and occupation in young and middle aged men. I Cancers of the respiratory tract. $\mathrm{Br} J$ Ind Med 1986;43: 332-8.

37 Boffetta P, Harris RE, Wynder EL. Case-control study on occupational exposure to diesel exhaust and lung cancer risk. Am J Ind Med 1990;17:577-91.

38 Costello J, Ortmeyer CE, Morgan WKC. Mortality from lung cancer in U.S. coal miners. American Journal of Public Health 1974;64:222-4.

39 Armstrong BK, McNulty JC, Levitt LJ, Williams KA, Hobbs MST. Mortality in gold and coal miners in Western Australia with special reference to lung cancer. Br J Ind Med 1979; 36:199-205.

40 Ames RG, Amandus H, Attfield M, Green RY, Vallyathan V. Does coal mine dust present a risk for lung cancer? A casecontrol study of U.S. coal miners. Arch Environ Health 1983; 38:331-3.

41 Martischnig KM, Newell DJ, Barnsley WC, et al. Unsuspected exposure to asbestos and bronchogenic carcinoma. BMJ 1977 i:746-9.

42 Selikoff IJ, Hammond EC, Seidman H. Mortality experience of insulation workers in the United States and Canada, 19431976. Ann N Y Acad Sci 1979;330:91-116.

43 Kvale G, Bielke E, Heuch I. Occupational exposure and lung cancer risk. Int J Cancer 1986;37:185-93.

44 Doll R, Peto $R$. The causes of cancer: quantitative estimates of avoidable risks of cancer in the U.S. today. $J$ Natl Cancer Inst 1981;66:1193-308.

45 Samet JM, Lerchen ML. Proportion of lung cancer caused by occupation: A critical review. In: Gee JB, Morgan WK, Brooks SM, eds. Occupational lung disease. New York: Raven Press, 1984:55-67.

46 Vinéis $\mathrm{P}$, Simonato L. Proportion of lung and bladder cancers in males resulting from occupation: a systematic approach. $\mathrm{Arch}$ Environ Health 1991;46:6-15.

47 Lilienfeld AM, Lilienfeld D. Foundations of epidemiology, 2nd ed. New York: Oxford University Press, 1980.

48 Stellman SD. Interactions between smoking and other exposures: occupation and diet. In Hoffmann D, Harris C, eds. Mechanisms in tobacco carcinogenesis. Cold Spring Harbor Laboratory, 1986:377-93. (Banbury report No 23.)

49 American Cancer Society. Facts and figures, 1991. Atlanta: ACS, 1991.

Accepted 6 January 1992 